\title{
Tying oneself to the mast: one necessary cost to morally enhancing oneself biomedically
}

Most of us try, in various ways and to varying degrees of success, to be better people. Over time we have developed a range of tools and techniques of varying efficacy to aid us in these efforts - we might seek the advice of others, make resolutions, read instructive works of fiction and non-fiction, and so on. In recent years, however, bioethicists have become increasingly interested in the idea that one day we might be able to 'morally enhance' ourselves through biomedical means. The actual development and manufacture of such 'biomedical moral enhancements' (hereafter BMEs) still looks some way off. ${ }^{1}$ However, even the prospect of such technologies has given rise to a vigorous debate in the philosophical literature on their ethical permissibility and desirability. A review from 2014, for example, found 85 articles published on the subject since $2008 .^{2}$

Proponents include Tom Douglas, David DeGrazia, Mark Walker, Ingmar Persson and Julian Savulescu. For Douglas, BMEs are moral permissible primarily because there is no good reason for thinking their use is morally objectionable. ${ }^{3}$ Persson and Savulescu go

\footnotetext{
${ }^{1}$ M. J. Crockett. Moral bioenhancement: a neuroscientific perspective. J Med Ethics. 2014; 40: 370-1; L. Arnhart. Can virtue be genetically engineered? Polit Life Sci. 2010; 29: 79-81.

${ }^{2}$ J. Specker, F. Focquaert, K. Raus, S. Sterckx, M. Schermer. The ethical desirability of moral bioenhancement: A review of reasons. 2014. BMC Medical Ethics, 15, 67.

${ }^{3}$ T. Douglas. Moral enhancement. J Appl Philos. 2008; 25: 228-245; T. Douglas. Moral enhancement via direct emotion modulation: a reply to John Harris. Bioethics. 2013; 27: 160-168.
} 
further, claiming that the use of BMEs is not only morally permissible but morally obligatory if we are to avert future catastrophe. ${ }^{4}$

Sceptics are, perhaps, more numerous. To being with, there are those who doubt whether such technologies are really feasible. We might be wonder, for example, whether we could ever reach a consensus as to what changes such technologies ought to bring about. ${ }^{5}$ It is also unclear whether, even if they were feasible, they would be particularly helpful. For example, far from enabling us to act morally, it seems possible that some BMEs may be detrimental in certain situations. ${ }^{6}$ Perhaps most problematically, some question whether the changes wrought by BMEs (as they are typically imagined) really constitute 'moral' enhancements in the way their proponents suggest; that is, whether they actually make us 'better people' in the way a moral enhancement should. ${ }^{7}$

Assuming, though, that we can find satisfactory responses to these kinds of issues, we might still ask whether actually taking a BME would incur any kind of moral cost, either to

\footnotetext{
${ }^{4}$ I. Persson \& J. Savulescu. The perils of cognitive enhancement and the urgent imperative to enhance the moral character of humanity. J App Phil. 2008; 25:162-177; I. Persson \& J. Savulescu. The turn for ultimate harm: a reply to Fenton. J Med Ethics. 2011; 37:441-444; I. Persson \& J. Savulescu. 2012. Unfit for the future: the need for moral enhancement. Oxford: Oxford University Press; J. Savulescu \& I. Persson. Moral enhancement, freedom and the God machine. Monist. 2012; 95: 399-421; I. Persson \& J. Savulescu. Getting moral enhancement right: the desirability of moral bioenhancement. Bioethics. 2013; 27: 124-131.

${ }^{5}$ J. R. Shook. Neuroethics and the possible types of moral enhancement. AJOB Neurosci 2012; 3: 3-14.

${ }^{6}$ N. Agar. Moral bioenhancement is dangerous. J Med Ethics 2015; 41: 343-345; D. Wasserman. When bad people do good things: will moral enhancement make the world a better place? J Med Ethics 2014, 40: 374-375; S. Chan \& J. Harris. Moral enhancement and pro-social behaviour. J Med Ethics 2011; 37: 130-131.

${ }^{7}$ W. Simkulet. Intention and moral enhancement. Bioethics 2016; 30: 714-720.
} 
the agent or to someone else. One set of worries writers have had here is how the use of BMEs might change the social and political landscape. Sparrow, for example, objects to BMEs partly on the grounds that they would likely grant the morally enhanced important advantages over the non-enhanced. ${ }^{8}$ Similarly, Brooks claims that moral enhancement might benefit some moral, philosophical, and religious doctrines over others, undermining the existence of a 'reasonable pluralism in modern liberal societies'.

Yet, insofar as these concerns relate to costs that taking BMEs might incur, we might still ask whether there are any moral costs necessarily incurred by using BMEs, that would be incurred in all possible worlds? One line of criticism that appears to meet this criteria are those that object to BMEs not on the grounds that they are biomedical interventions designed to enhance ourselves morally but rather on the grounds they are biomedical interventions designed for the purposes of enhancement, the entire project of biomedical enhancement already being morally dubious for a variety of reasons (for example, because it is 'unnatural', or because it perpetuates the (false) idea that we ought to strive toward perfection). ${ }^{10}$

\footnotetext{
${ }^{8}$ R. Sparrow. Egalitarianism and moral bioenhancement. Am J Bioethics 2014; 14: 20-28. Another spin on this kind of objection has recently been put forth by Archer, who argues that 'the widespread use of moral enhancement would raise the standards for praise and blame worthiness, making it much harder for the unenhanced to perform praiseworthy actions or avoid performing blameworthy actions' (A Archer. Moral enhancement and those left behind. Bioethics 2016; 30: 500-510).

${ }^{9}$ T. Brooks. Moral Frankensteins. AJOB Neurosci 2012; 3: 28-30. A similar argument here is made by Schaefer, who contends that 'large-scale programs of direct moral enhancement contain a serious flaw, insofar as they will suppress dissent' (G. O. Schaefer. Direct vs indirect moral enhancement. KIEJ 2015; 25: 261-289).

${ }^{10}$ See, e.g., M. J. Sandel. 2009. The case against perfection: what's wrong with designer children, bionic athletes, and genetic engineering. In Human enhancement. J. Savulescu \& N. Bostrom, eds. Oxford: Oxford University Press: 71-90
} 
However, again, one shortcoming of this line of criticism is that it does not pick out any problem with BMEs in particular, which is to say, incurred by virtue of the fact that they are biomedical enhancements directed towards making us better people, as opposed to any other kind of biomedical enhancement. Specifying our question even further, then, we might now ask whether there are any moral costs necessarily incurred by using BMEs, that would be incurred in all possible worlds, and that are not derived simply by virtue of the fact that they are one method by which we might enhance ourselves biomedically?

In this essay, I argue that there is one such cost, namely the limitations BMEs impose on our freedom. This line of criticism is far from novel, having already been voiced by a range of authors, most notably, perhaps, by John Harris. ${ }^{11}$ However while there is much in this article that owes a debt to Harris, the argument I lay out here differs from his in a number of crucial respects. To begin with, I offer an alternative account of the nature of the restriction BMEs impose on our freedom, one which attempts to incorporate a number of what I take to be valid counter-arguments to Harris's original thesis. The analysis I offer here also differs from Harris in what I take to be the moral implications of that restriction. For Harris, the problem with the threat BMEs pose to our freedom was primarily about their ramifications for our moral responsibility. Following concessions to Harris's opponents, however, I argue that the moral costs incurred by BMEs are better understood in terms of the value we attach to precisely those freedoms BMEs restrict. This analysis does not suggest that there may not be some cases where, through further intervention, we are able to forestall the moral costs incurred by BMEs, nor that the imposition of such costs may not be justified by some

\footnotetext{
${ }^{11}$ J. Harris. Moral enhancement and freedom. Bioethics. 2011; 25: 102-111; J. Harris. Ethics is for bad guys! Putting the 'moral' into moral enhancement. Bioethics. 2013; 27: 169-173.
} 
attendant set of benefits. However, it does suggest that, at the point at which they are taken, all BMEs necessarily incur at least some moral cost.

The paper proceeds as follows. In Section One, I outline the kind of BMEs I will be discussing in the analysis to follow, which is to say, those BMEs by which we might attempt to make ourselves agents with morally better motives. In this section, I also explain a little bit about how such enhancements are imagined to work. In Section Two, I consider how BMEs might affect our freedom, while in Section Three I turn to the ethical significance of these effects. In Section Four, I consider a few counter-arguments to my position as well as its implications for the debate around BMEs generally. I conclude in Section Five.

\section{Biomedical moral enhancements}

What kind of technologies are we talking about when we talk about 'biomedical moral enhancements'? To a certain extent, this phrase may be read fairly loosely. By 'moral enhancement', one might mean any number of ways in which we might seek to be better people (in a moral sense). Following Douglas, this could include making ourselves more virtuous or more praiseworthy, making ourselves more capable of moral responsibility or more likely to behave or act more morally, making ourselves agents with morally better motives and so on. ${ }^{12}$ Similarly, by 'biomedical means', one might mean a range of possible technologies including pharmaceuticals, somatic gene therapy, germ line gene therapy; transcranial magnetic stimulation, deep-brain stimulation, transcranial direct current

\footnotetext{
12 Douglas, Moral enhancement, op. cit. note 3.
} 
stimulation, optogenetics, surgical interventions, and so on - even some future gadgetry beyond our imagination.

In order to focus the terms of our analysis, however, in this article I want to consider the ethical acceptability of just those biomedical technologies (actual or possible) by which we might make ourselves agents with morally better motives. Since this is the kind of BME which is discussed most often by those seeking to defend them from their real, or imagined, detractors, one benefit of centring our discussion on these technologies in particular is that it helps ensure we are meeting any possible opponents on their own ground.

One example of the kind of BME we might be thinking of here, then, would be Douglas's suggestion of a BMEs capable of attenuating our 'counter-moral' emotions, such as a bias against people of a certain race:

Example A: James is a district court judge in a multi-ethnic area. He was brought up in a racist environment and is aware that emotional responses introduced during his childhood still have a biasing influence on his moral and legal thinking. For example, they make him more inclined to counsel jurors in a way that suggests a guilty verdict, or to recommend harsher sentencing, when the defendant is African-American. A drug is available that would help to mitigate this bias. ${ }^{13}$

Persson and Savulescu also discuss similar kinds of technologies, reflecting on the possibility of administering oxytocin for its 'pro-social effects' and selective serotonin reuptake

\footnotetext{
${ }^{13}$ Douglas, Moral enhancement via direct emotion modulation, op. cit. note 3.
} 
inhibitors (SSRIs) to enhance our moral dispositions, on the grounds that there is some evidence that they make subjects more 'fair-minded and willing to cooperate' with others. ${ }^{14}$

One point that will be crucial to bear in mind in what follows is how exactly Douglas, Persson and Savulescu imagine these interventions would work. For Douglas, the kind of pharmaceuticals he wants to talk about would work by influencing those psychological — mental or neural — states or processes that will, given the absence of opposing motives, cause a person to act. ${ }^{15}$ There seem to be a few ways in which this might happen. To begin with, such technologies may influence my psychological states or processes either by preventing certain states or processes from arising, or preventing those states or processes that do arise from influencing one's moral thinking. The thought here, then, is that such technologies stop those states or processes that without the BME, and in absence of opposing motive, would have caused me to act, thereby leaving me to reason unimpeded. In what follows I shall refer to this as biomedical moral enhancement through mitigation.

A good example of this kind of biomedical moral enhancement is Douglas's biased judge example cited above. As Douglas explains, in this case James thinks his legal and moral thinking is, in general, directed towards the good. However, he also recognises that he has another set of desires and dispositions that are not directed towards the good and have the tendency to affect him in his final judgement. Douglas's imagined drug, then, helps James morally enhance himself by diminishing or arresting those desires he worries may wrongly influence his moral judgement and allow him to continue reasoning unimpeded.

\footnotetext{
${ }^{14}$ Persson \& Savulescu, Unfit for the future, op. cit. note 4.

${ }^{15}$ Douglas, Moral enhancement, op. cit. note 3.
} 
One reason Douglas is keen to alert us to this kind of scenario is because it helps forestall one possible objection to BMEs. For example, it could be argued that insofar as BMEs bring about certain emotional responses within us, they could not really be considered moral improvements at all (our emotions not constituting a proper subject of ethical evaluation). Now Douglas thinks (quite rightly, to my mind), ${ }^{16}$ that this is mistaken, that our emotions can be the proper subject of ethical evaluation. However, he also wants to say that even if we disagree on this point, we might still think BMEs are capable of bringing about moral improvements since some BMEs could work by mitigating against any corrupting influence the emotions have on our normal cognitive processes. ${ }^{17}$

Yet, even if Douglas is keen to alert us to the possibility of this kind of BME in particular, it seems clear that other BMEs might work in exactly the opposite way: namely, by creating certain states or processes within one's mind that might not otherwise exist, or by supplementing those states or processes that do arise to be more prominent than they might otherwise be (without necessarily being sufficient to 'overcome' one's moral thinking). For

\footnotetext{
${ }^{16}$ In this, I tend to follow William's lead: 'Some of what I have to say may seem too psychological. In one respect, I make no apology for this...in as much as I think that a neglect of moral psychology and in particular of the role of emotion in morality has distorted and made unrealistic a good deal of recent discussion; having disposed of emotivism as a theory of the moral judgment, philosophers have perhaps tended to put the emotions on one side as at most contingent, and therefore philosophically uninteresting, concomitants to other things which are regarded as alone essential This must surely be wrong: to me, at least, the question of what emotions a man feels in various circumstances seems to have a good deal to do, for instance, with whether he is an admirable human being or not.' (B. A. O. Williams. Ethical Consistency. Proc Arist. Soc., Suppl. Vols. 1965; 39: $103-138)$.

${ }^{17}$ Douglas, Moral enhancement, op. cit. note 3; Douglas, Moral enhancement via direct emotion modulation, op. cit. note 3 .
} 
example, take Douglas's biased judge, James. In this case we might imagine that James's moral enhancement works not by diminishing or arresting his bad emotional responses to people of a different race but by, say, creating within him a general feeling of fraternity and common humanity, or by strengthening a general feeling of fraternity and common humanity that he already has so that it has a stronger (though not decisive) bearing on his decision making. In what follows I shall refer to this as biomedical moral enhancement through augmentation.

To sum up, then, the kind of biomedical moral enhancements I want to assess here are those biomedical interventions (actual or possible) by which we might try to a) prevent certain states or processes from arising; b) prevent those states or processes that do arise from influencing our moral thinking; c) create certain states or processes within our mind that might not otherwise exist; or d) supplement those states or processes that do arise so that they are more prominent than they might otherwise be; all with the overall aim of making ourselves morally better people in the sense of being agents with morally better dispositions.

\section{BMEs Effect on Our Freedom}

If this is what we mean when we talk about BMEs, is there anything we might find morally troubling about using such technologies? As intimated earlier, one of the more heated debates around the ethical acceptability of BMEs centres on their effect on our freedom, or liberty.

The first writer to make this point was John Harris. In what has subsequently become known as his 'Freedom to Fall' argument, Harris claimed that the problem with the kinds of 
BMEs advanced by writers like Douglas, Persson and Savulescu was that they made it impossible for us to do immoral things. ${ }^{18}$ As Harris explained, by mitigating or augmenting certain dispositional states (among other things), such technologies effectively closed the gap between 'knowing the good' and 'doing the good', meaning that insofar as we 'did the good', we could not be said to be doing it as the result of a choice but as the result of a BME. ${ }^{19}$ Thus, whenever one takes BMEs, 'then the morally enhanced action [that results] is effectively automatic, unconscious and therefore unintended'.

This argument has been met with a series of rebuttals. Douglas, for example, has contested the claim that BMEs are always entirely restrictive on our freedom, writing:

[S] uppose that I undergo an intervention that mitigates some of the many emotional biases that afflict my prudential and moral reasoning, or that reduces my temptation to act against my sincere normative judgements. This intervention seems aptly characterized as increasing my freedom to be moral by removing a brute constraint on that freedom. At least, it is difficult to see how my freedom to be immoral has decreased by that change. ${ }^{20}$

Elsewhere, DeGrazia has argued that, contra-Harris, there is no reason to suppose that the moral behaviour of those who have undergone biomedical moral enhancement would necessarily or routinely fail the necessary conditions of free, or what he terms 'autonomous',

\footnotetext{
${ }^{18}$ Harris, Moral enhancement and freedom, op. cit. note 11.

${ }^{19}$ Ibid.

${ }^{20}$ Douglas, Moral enhancement via direct emotion modulation, op. cit. note 3. A few months after Douglas's rejoinder, Harris responded in turn (Harris, Ethics is for bad guys!, op. cit. note 11). However, while countering Douglas on a number of other issues, Harris fails to respond to this precise point.
} 
action: namely i) that $\mathrm{A}$ does $\mathrm{X}$ because she prefers to do $\mathrm{X}$; ii) that $\mathrm{A}$ has this preference because she (at least dispositionally) identifies with and prefers to have it; and (iii) that this identification has not resulted primarily from influences that A would, on careful reflection, consider alienating' ${ }^{21}$

Both of these responses have their merits. First, following DeGrazia, insofar as we take Harris to be claiming that any action taken partly or wholly as the result of a BME cannot be considered intentional or reflective of the "considered moral values of the individuals making them', it seems clear that that claim is false. Rather, if we assume P took their BME voluntarily and in full knowledge its effects on their subsequent action, then it looks like we would say, of any of P's actions that were the result of their having taken the BME, that they reflect P's considered values, simply by virtue of the fact that they reflect the kind of actions $\mathrm{P}$ intended to bring about by taking the BME, when they took the BME they did. Of course, there may be certain cases in which agents change their 'considered values' between the time they took the BME and the time its effects are felt. In these kinds of cases, any subsequent action they took as a result of their having taken the BME would seem to fail to reflect their considered values. In turn, this would raise questions about alienation. ${ }^{22}$ However, in those cases in which agents do not undergo such changes - in cases where their preferences and considered values remain stable (i.e. DeGrazia's second condition of

\footnotetext{
${ }^{21}$ D. DeGrazia. Moral enhancement, freedom, and what we (should) value in moral behaviour. J Med Ethics. 2013. Harris has again responded to this rejoinder, taking issue with DeGrazia's conclusions partly because of the 'ambiguity and subjectivity' of DeGrazia's third criteria for autonomous action. (J. Harris, Taking liberties with free fall. J Med Ethics, 2014; 40: 371-374).

${ }^{22}$ For more on this see, e.g. F. Focquaert \& M. Schermer. Moral enhancement: do means matter morally? Neuroethics. 2015; 8: 139-151.
} 
autonomous action) - it seems difficult to motivate the same concerns. Thus, while the spectre of alienation looks like a valid concern with respect to some BMEs in some circumstances, it does not look like a moral cost BMEs would incur in all possible worlds.

Following Douglas, and seemingly contra-Harris (or, at least, a quick reading of Harris), it also looks like there may also be cases in which BMEs grant us freedoms previously unavailable to us. To a certain extent, the precise way Douglas puts this - that is, in terms of 'increases' or 'decreases' to one's general freedom - can get us into thorny territory with regards to how specific freedoms (P's freedom to do $x$ ) relate to one's overall freedom (P's freedom tout court) ${ }^{23}$ For example, although it is not a position with which I agree, some writers would deny that it makes any sense whatsoever to talk of freedom as a quantitative attribute, that there is any such as freedom tout court but rather only specific freedoms. ${ }^{24}$ As S. I. Benn and R. S. Peters put it, 'liberty is not a commodity to be weighed and measured. I am free to do $\mathrm{x}, \mathrm{y}$, and $\mathrm{z}$, but not to do $\mathrm{p}, \mathrm{q}$, and $\mathrm{r}-$ but there is no substance called "freedom" of which I can therefore possess more or less'. ${ }^{25}$ However, if we take Douglas's point here to be the more modest suggestion that, in mitigating against those dispositional states that would otherwise hinder one's ability to act in a way reflective of one's considered values, BMEs might confer upon us certain specific freedoms which were otherwise barred, then it would be difficult to conclude that the only influence any BME can have on our freedom is in removing freedoms which we otherwise enjoyed (one reading, perhaps, of Harris's position).

\footnotetext{
${ }^{23}$ I. Carter. 1999. A measure of freedom. Oxford: Oxford University Press: 14-19.

${ }^{24}$ R. Dworkin. 1985. A matter of principle. Cambridge, Mass.: Harvard University Press: 189.

${ }^{25}$ S. I. Benn \& R. S. Peters. 1959. Social principles and the democratic state. London: Allen and Unwin: 214.
} 
Finally, if we take Harris's claim that biomedical moral enhancements make 'the freedom to do immoral things impossible' as a claim to the effect that the kind of BMEs championed by Douglas and others necessarily preclude one from being able to behave immorally, then that claim also looks highly debatable. ${ }^{26}$ The problem here is that this claim rests on the assumption that one's current dispositional state is the only determinate of one's future behaviour. Yet, if not false, at the very least this looks open to reasonable disagreement. $^{27}$

Despite these concessions, though, I think it would be wrong to dismiss Harris's concerns about BMEs effect on our freedom entirely. Before further defending this line of criticism, however, we first need a more definite account of what we mean by freedom. Indeed, if there is one criticism that might be levelled at the current debate is that it can sometimes appear to be unnecessarily ambiguous on this point, sometimes seeming to drift

\footnotetext{
${ }^{26}$ Harris, Moral enhancement and freedom, op. cit. note 11.
}

${ }^{27}$ A further objection to Harris's argument which I do not consider here is raised by Savulescu and Persson, who claim that individuals' freedom could never be threatened by BMEs, assuming that they augment individuals' moral dispositions (Persson \& Savulescu, Getting moral enhancement right, op. cit. note 4). However, as Bublitz points out, the salient point here is not what dispositions BMEs create but rather how they create them. As Bublitz explains, 'S\&P too easily pass over a very influential variation of compatibilism which denies responsibility if persons act on preferences that were brought about through manipulation...[the central idea of this position] is that autonomy is a historical phenomenon, which means that apart from sufficient capacities in the moment of action, the genesis of preferences leading to action is relevant... What matters is how they acquired their preferences and became the persons they are'. (C. Bublitz. Moral Enhancement and Mental Freedom. J App Phil. 2016; 33: 88-106). 
between several competing conceptions. ${ }^{28}$ For example, based on his interest in what BMEs make it 'impossible' for us to do, Harris can seem to endorse a conception of freedom which takes it to be a matter of the absence of certain preventing conditions on agents' possible action - as in MacCallum view of freedom, ${ }^{29}$ or Carter's. ${ }^{30}$ By contrast, DeGrazia appears to take freedom as a matter of being able to do (or not being prevented from doing) what one prefers to do (albeit with certain caveats). The conflict between these two positions is brought out in particular by DeGrazia's discussion of the extent to which our freedom is dependent upon our ability to do otherwise. For DeGrazia, then, part of the reason BMEs do not pose a threat to freedom is that freedom itself is not necessarily dependent upon our ability to do otherwise but rather that one is able to do what one prefers to do, or what follows from one's 'stable values'. As DeGrazia explains:

I am psychologically incapable of stabbing or shooting a person I perceive to be innocent and non-threatening... But my inability here is not due to squeamishness, for I could probably stab or shoot someone who was trying to kill a loved one or an innocent person if no less violent means of protection were available. My inability to stab or shoot a loved one or innocent person is due to my stable values and preferences. I freely abstain from immoral assault even though I cannot act otherwise. ${ }^{31}$

\footnotetext{
${ }^{28}$ B. Beck. Conceptual and practical problems of moral enhancement. Bioethics 2015; 29: 233-240.

${ }^{29}$ G. MacCullum. Negative and Positive Freedom. Phil Review 1967; 76: 312-34.

${ }^{30}$ Carter, op. cit. note 24 .

${ }^{31}$ DeGrazia, op. cit. note 21.
} 
The debate between these two broad conceptions of freedom continues to be a highly contentious subject in philosophy, suggesting that at least some of the debate around BMEs may be a kind of proxy war for more general philosophical differences. Overall, however, I find myself more sympathetic to Harris's conception of freedom than DeGrazia's. First, like other writers endorsing similar positions, DeGrazia's view seems to confuse 'being free' with 'feeling free'. As Carter puts it,

If I am prevented from doing $x$, although I may not 'feel' the unfreedom to do $\mathrm{x}$ (because $\mathrm{x}$ is, for me, a worthless option), this is not to deny that I am unfree to do $x$. A prison inmate who places no value whatever on going to the theatre is nevertheless unfree to go to the theatre. ${ }^{32}$

Furthermore, again following Carter, it seems to me that the question of how an agent's preferences relates to their freedom is best dealt with not at the point of definition of an agent as free but rather in respect to the value we attach to the freedoms they have. ${ }^{33}$ In other words, the problem with positions such as DeGrazia's is that they blur the distinction between what freedoms an individual could be said to have and the value of those freedoms, defining as freedoms/unfreedoms only those courses of action that relate in the right way to the agent's values (or preferences) and dismissing any other impediments to an agent's possible action as, in an important sense, irrelevant to the question of their freedom. ${ }^{34}$

\footnotetext{
${ }^{32}$ Carter, op. cit. note 24, p. 113. Cf. H. Steiner. Individual liberty. Proceedings of the Aristotelian Society. 1974-5; 75 .

${ }^{33}$ Carter, op. cit. note 24, p. 113.

34 To a certain extent, DeGrazia can be a little slippery on this point. For example, after having stressed that the 'ability to act otherwise, or freedom to fall, is not a necessary condition of free action', DeGrazia goes on to
} 
In what follows, then, I take freedom to be the absence of certain preventing conditions on agents' possible action. Moreover, I reserve discussion of what significance we should attach to those conditions that prevent an agent from pursuing a course of action they have no particular interest in (do not value or prefer, or, upon careful reflection, might come to prefer) to later discussions about the value of freedom (or freedoms), rather than taking them as relevant to the question of whether or not a given agent is free (see Section Three below).

Assuming this conception of freedom, then, what more might be said for Harris's line of criticism against BMEs? One thing that I believe has been lost in this debate, particularly in all the talk as to BMEs effect on our overall freedom, is that even if Douglas is right to think that BMEs may act as a net contribution to our overall freedom, or at least grant us specific freedoms from which we would otherwise be barred, simply by virtue of the fact that they determine one's future dispositions to follow a particular course (whether in augmenting

claim that 'Nevertheless, some conceivable forms of MB would pose a threat to freedom. Imagine a computer chip that could be implanted in someone's brain such that whenever the agent decided to perform a certain kind of immoral action, he would change his mind. The implant would reliably, automatically redirect his decisionmaking. It seems plausible to assert that this sort of $\mathrm{MB}$ would make an agent unfree with respect to certain actions (even if the agent welcomed the MB), and possibly in motivation-based ways—-say, if it made the agent suddenly lose the desire to perform the action in question. But most of the types of MB under consideration, including the examples enumerated earlier, do not have this apparently freedom-robbing quality.' (DeGrazia, op. cit. note 21) In this way, then, DeGrazia seems to acknowledge that our freedom can be 'threatened' insofar as the ability to act otherwise is restricted and that one's freedom to do what one prefers is not a sufficient condition of freedom (the agent having 'welcomed' the BME). As a further aside, it should also be noted that one of points made in the analysis to follow is that far from being a relatively rare phenomenon with regards to BMEs, this 'freedom-robbing quality' is, in fact, a necessary feature of all BMEs. 
dispositions or mitigating), BMEs necessarily take away other specific freedoms which we would have otherwise have enjoyed.

For example, say that $\mathrm{P}$ takes an augmentative $\mathrm{BME}$ at $\mathrm{T} 1$ in order to create disposition $\mathrm{x}$ at $\mathrm{T} 2$. In this case, regardless of whether or not having disposition $\mathrm{x}$ at $\mathrm{T} 2$ increases or decreases P's overall freedom, (or grants her specific freedoms she would have otherwise foregone), by taking the augmentative BME P necessarily determines herself to have the disposition that intervention brings about at the time its effects are felt. Thus, by taking the BME, $\mathrm{P}$ effectively removes two possible courses of action previously open to her: (i) the possibility of not having $\mathrm{x}$ at $\mathrm{T} 2$, and (ii) the possibility of having $\mathrm{x}$ at $\mathrm{T} 2$ as the result of some other means (say a decision) taken between T1 and T2. ${ }^{35}$ Similarly, if P were to take a mitigatory $\mathrm{BME}$ at $\mathrm{T} 1$, designed to prevent $\mathrm{x}$ from arising within her at $\mathrm{T} 2$, she would effectively be removing two possible courses of action previously open to her: namely, the possibility of having $\mathrm{x}$ at $\mathrm{T} 2$ and the possibility of not having $\mathrm{x}$ at $\mathrm{T} 2$ as the result of some other means taken between $\mathrm{T} 1$ and $\mathrm{T} 2{ }^{36}$

\footnotetext{
${ }^{35}$ One assumption here, of course, is that insofar as one takes a BME at $\mathrm{T} 1$ to have disposition $\mathrm{x}$ at $\mathrm{T} 2$, that causal path cannot be superseded by some further decision one takes between T1 and T2 to also have disposition $\mathrm{x}$ at $\mathrm{T} 2$. In other words, then, the causal path created by the BME cannot be 'trumped' by a subsequent decision. Admittedly, there may be those who question this view but it seems to me to be a reasonable one. Certainly, it seems difficult to understand how subsequent decisions could 'override' the kind of physical process begun by a BME, or indeed what 'overriding' such processes would mean in this context.

${ }^{36}$ At this point, one might object that all BMEs may not have this effect in all possible worlds, for it may be that the possibility of having $\mathrm{x}$ at $\mathrm{T} 2$, and the possibility of not having $\mathrm{x}$ at $\mathrm{T} 2$ as the result of some other means taken between T1 and T2 was never open to P to begin with, as such the BME has imposed no loss on her freedom. However, I take that the discussion about the ethical acceptability of BMEs looks to those possible
} 
Now it may be that, in some further subset of the possible worlds in which $\mathrm{P}$ takes the BME, $\mathrm{P}$ has resources at her disposal that allow her to interrupt this causal pathway. Perhaps, the BMEs effects are reversible and she has both access to an antidote and time to use it between T1 and T2. However, the important point here is that, irrespective of whether or not $\mathrm{P}$ has the resources to forestall this restriction to her freedom, simply by virtue of the way the BME works, at the point at which $\mathrm{P}$ takes the BME, (T1), this restriction has necessarily been imposed and would be imposed in all possible worlds. Where, then, it is not possible for $\mathrm{P}$ to forestall this restriction - say, because the BMEs effects are irreversible, or she does not access to the relevant antidote - that restriction would be permanent. However, even where it is possible for $\mathrm{P}$ to remedy such a restriction, any such remedy will still require some further action either by her, or that of another party. From this, then, we might recognize that there is a deterministic element about BMEs, one which may be more or less irrevocable depending on the case in hand, yet one that is also undoubtedly deterministic and which is engendered in all possible worlds. ${ }^{37}$

worlds in which it actually has an effect, which is to say, that it is not redundant. Therefore, I take these possibilities to be irrelevant to the present analysis.

${ }^{37}$ Bublitz makes an analogous point here about the 'freedom of the mind' (Bublitz, op. cit. note 28). In the end, my thesis does not entirely agree with Bublitz's - for example, I am not entirely convinced that freedom of the mind (in the sense I mean it) requires conscious control over one's mind (as it does for Bublitz). Moreover, in this article I try to motivate the moral cost to BMEs in a slightly different way to Bublitz. However, this being said, there are clearly many points of agreement between his thesis and my own and hence, they may be seen as offering broadly comparable critiques of BMEs. 


\section{Why the restrictions BMEs impose on our freedom matter.}

In light of the previous section, we now seem to have a clear sense in which BMEs necessarily impose a restriction on our freedom, albeit one which may be forestalled in certain cases. Nevertheless, we might ask, regardless of whether the agent in question is able to forestall such a restriction, why should we think that restriction matters morally? That is, why think that the freedoms BMEs take from us are of any moral cost to the agent who finds themselves so restricted?

For Harris, the problem with BMEs is that, in removing freedoms - and specifically our 'freedom to fall' - such technologies undermine any sense in which we are morally responsible for subsequent actions, putting them 'entirely outside the realm of moral responsibility and probably of criminal responsibility also' ${ }^{38}$ Indeed, it is partly for this reason that Harris concludes that 'biomedical moral enhancements' should not really be counted as 'moral enhancements' at all. Such enhancements do not present us with any new reasons for action, they do not make us, in Harris's phrase, 'better at knowing the good and understanding what is likely to conduce to the good'. ${ }^{39}$ Rather, 'bypassing cognition' entirely, they only render us more likely to perform good actions; ${ }^{40}$ and, as Harris puts it, "there is no virtue in doing what you must'. ${ }^{41}$

\footnotetext{
${ }^{38}$ Harris, Ethics is for bad guys!, op. cit. note 11.

${ }^{39}$ Harris, Moral enhancement and freedom, op. cit. note 11.

${ }^{40}$ Harris, Ethics is for bad guys!, op. cit. note 11.

${ }^{41}$ Harris, Moral enhancement and freedom, op. cit. note 11.
} 
Given the concessions we have made to Harris's opponents above, though, it now looks like this particular argument is going to face a number of problems. First, while we might recognise that all BMEs 'bypass cognition' in the way they work, following Douglas's counter, we might also think that some BMEs - most notably BMEs that work through mitigation - may actually allow us to cognize better than we would have otherwise been able. Far from undermining moral responsibility, then, it could be that we are more responsible for actions we take while in a biomedically 'enhanced' state (say, one free of dispositions we recognise as disruptive) than those we undertake absent such treatments (on the assumption that the latter set of actions are less likely to reflect our considered views on a given matter).

Second, even when we restrict Harris's criticism simply to those BMEs that work through augmentation, insofar as we assume that a) the BME was taken voluntarily, b) our dispositional state is not the only determinant of our behaviour - both of which look reasonable - it looks difficult to motivate the view that we are not responsible for any action we make while being in a biomedically 'enhanced' state, for in such a case, we would still be responsible for both having taken the BME and acting on the basis of the dispositional state caused by the BME.

Thus while it seems clear that Harris is right to think that BMEs impose certain restrictions on our freedom, when we clarify exactly what kind of restrictions these technologies are imposing, it does not look like the type of restriction that would necessarily undercut moral responsibility (or at least, the kind of moral responsibility we usually care about). However, that being said, there still seems good reason to think the deterministic elements of BMEs are morally troubling, namely simply in virtue of the freedoms they subtract. 
There are two ways that this thought might go. First, one might hold that the limitations BMEs impose on our freedoms come at a certain moral cost because those freedoms the BMEs remove have a certain value, and the reason they have that value is specifically by virtue of what they allow us to do. For example, on Kymlicka's conception of freedom's value, specific freedoms are valuable to the extent that they serve some set of interests. As he puts it, "the reason it is important to be free in a particular respect is not the amount of freedom it provides, but rather the importance of the various interests it serves'. ${ }^{42}$ One reason we may find BMEs troubling, then, is that we value our ability to affect our dispositional state (either in having or not having certain dispositions) and that therefore we attach a certain value to our specific freedom to change our dispositions as we see fit.

As well as such freedoms having value in this respect, however, Carter gives us good reason to believe that they might also have what he calls non-specific value, which is to say, that we might value freedoms 'independently of the value we attach to the specific things they leave us free to do' ${ }^{43}$ In defending this position, Carter draw our attention to both to freedom's instrumental value (for example, as a means to individual well-being) and the intrinsic value we place on our 'agency', which is to say, 'our ability to make an impact on the world, by intervening in the causal chains which bring about events and states of affairs'. ${ }^{44}$ It is for these kinds of reasons, then, that, irrespective of what our choices get us, we still tend to value having more choice rather than less.

\footnotetext{
${ }^{42}$ W. Kymlicka. 2002. Contemporary political philosophy: An introduction. Oxford: Oxford University Press: 148.

${ }^{43}$ Carter, op. cit. note 24, p. 33.

${ }^{44}$ Ibid: 42. In his Anarchy, State, and Utopia, Robert Nozick describes a thought experiment that appears to bring out the value of such 'doings' beautifully. Imagine, Nozick says, that there was an 'experience machine'
} 
One reason that this latter point is important is because it provides an extra buffer against a possible objection to the present account following from DeGrazia's defence of BMEs. For example, it might be argued that insofar as BMEs restrict our freedom to have dispositions that are potentially morally troubling (or not have those that are morally virtuous), they curtail a freedom of no real value to begin with. (Indeed, insofar as one defines freedom as not being prevented from doing what one prefers, or values, as DeGrazia seems to, such disvalued options would not count as freedoms at all). Now, to a certain extent, this objection already labours under a misapprehension insofar as it appears to suggest that the costs imposed by BMEs derive from the value we attach to having dispositions that are potentially morally troubling or not having dispositions we recognize as morally virtuous. However, on the analysis above, insofar as the costs imposed by BMEs derive from any interest we have whatsoever, they do not derive from the value we attach to having morally troubling dispositions or not having morally virtuous dispositions, but rather the value we attach our ability to affect our dispositional state - one such capacity being our ability to resist having dispositions we recognize as morally troubling and another being our ability to have dispositions we recognize as morally virtuous. Yet even if we were to be persuaded that that ability was of no real value - and hence, by Kymlicka's lights, our freedom to exercise such an ability could be of no real value - given freedom itself has a non-specific value, we

that could give you any experience you desired, neuropsychologists being able to stimulate your brain in such a way that you would think and feel like you were writing a great novel, or making a friend. Would you use such a machine? Nozick surmises, fairly reasonably, that normally we would not. And, as he explains, the reason for this is that we do not merely value experiencing things but actually doing them (R. Nozick. 1974. Anarchy, state and utopia. London: Blackwell: 42-3). 
might still say that there is a moral cost to the freedoms BMEs preclude, 'independently of the value we attach to the specific things they leave us free to do'. ${ }^{45}$

Of course, there may be those who are still sceptical about whether the freedoms BMEs remove have the kind of value I have suggested they do. However, whatever kind of value such freedoms do have, I think it is relatively clear that they do at least possess some value. One way we might see this, perhaps, is that we tend to balk at any situation in which we are forced to give them up. Consider, for example, the case of Ulysses and the Sirens. As legend would have it, in order to pass by safely the Island of the Sirens, Ulysses instructs his crew to tie him to the mast of the ship, so that he might hear the Sirens' song without being lured to his death. Interestingly, Persson and Savulescu use this example as a way of defending mitigatory BMEs, writing: 'we see how it is sometimes necessary to frustrate some of a person's desires, even his strongest desires, if we are to respect his autonomy' ${ }^{46}$ As above, insofar as this view seems to suggest that what BMEs take from one hand, they may give with another, I find myself fairly sympathetic to it. However, even if we can agree with Persson and Savulescu that Ulysses's actions were overall justified, it also seems plain enough that they are not actions we would normally want to undertake. That is, we would not normally consider it a 'good thing' to be tied to a mast. Rather, it seems clear enough that one of the few reasons that we would accept such a restriction is if it were necessary, that is, if we knew that without such restraints we would commit acts in direct conflict with our deepest commitments. Regardless, then, of whether Ulysses actions may be overall justified given his predicament, we can still recognise that they come at a moral cost, that tying oneself to a

\footnotetext{
${ }^{45}$ Carter, op. cit. note 24 , p. 33.

${ }^{46}$ Savulescu \& Persson, Moral enhancement, freedom and the God machine, op. cit. note 4.
} 
mast is not a good or even morally neutral way to live one's life. And it is this cost, it seems, which is necessarily incurred by morally enhancing oneself biomedically.

\section{Objections and Replies}

How might a proponent of BMEs respond to the arguments made in this article? One move they may make here is to claim that, in their deterministic or freedom-robbing effects, there is little difference between BMEs and a number of other, more 'traditional' means by which we might morally enhance ourselves. ${ }^{47}$ Take, for example, a monk who, after years of 'aversion therapy', repeating mantras and so on, has 'conditioned' themselves such that they are unable to feel the lure of earthly pleasures. Like someone taking a BME, then, in this case it looks like the monk, at T1, has taken a course of action that will ensure (subject to no further intervention), they will not experience a given disposition at T2. Are we really ready to tar these strategies with the same brush we applied to BMEs?

One response to this might be to question whether the two cases are really alike. One disanalogy we might note between the monk's process of conditioning and BMEs, for example, is the effectiveness of the intervention, that is, the extent to which it actually succeeds in changing an individual's dispositional state. This point is significant because, of course, all the costs the present analysis attaches to BMEs are premised on the assumption that they actually work, which is to say, that they actually do bring about the effects they are designed to bring about. If, then, we were to assume that, as it happens, the kinds of

\footnotetext{
${ }^{47}$ This objection mirrors a similar one by Douglas, who asks whether we can reasonably differentiate mitigatory BMEs from other ways in which we might stop ourselves from feeling certain desires and dispositions. Douglas, Moral enhancement via direct emotion modulation, op. cit. note 3.
} 
techniques used by the monk are far less effective in actually changing their dispositional state than, say, a BME would be, then we might similarly adjust their potential moral cost.

However, let us assume for the sake of argument that the technique does work, or works at least as well as a BME. Would then the process bear the same moral costs? On this point I find myself fairly willing to bite the bullet. That is, it seems to me fairly intuitive that insofar as these kinds of strategies are also methods by which we might determine ourselves to be better people, they are also strategies that come at some moral cost: the freedoms they prevent us from enjoying. ${ }^{48}$ This conclusion is likely to jar, not least because our natural assumption may be that the monk's actions have no moral cost, or, if they do, it is a vanishingly small one. In mitigating against this possible reaction, let me say two things. First, as made clear in Section Two, insofar as the present analysis identifies a moral cost necessarily incurred by all BMEs, it also suggests that such costs may be greater cause for concern in some cases than in others, simply by virtue of the fact that we may be more or less able to forestall them. Just as we might think, then, that some BMEs pose a less of a threat to

\footnotetext{
${ }^{48}$ I also take this bullet-biting to extend to cases where individuals are born unable not to feel certain conditions. For example, one objection writers have raised to accounts such as the present one is they can seem to run counter to our intuitions that those who are born with, say, a disproportionately high level of empathy, are just as free as anyone else. The thought being that if we do not consider people who are genetically predetermined to experience certain dispositions as 'less free' than we are, why should we think that BMEs restrict our freedom when their effects are essentially identical? (See, e.g., DeGrazia, op. cit. note 21; Persson \& Savulescu, Unfit for the future, op. cit. note 4; and V. Rakic. Voluntary moral enhancement and the survival-at-any-cost bias. $J$ Med Ethics 2014; 40: 246-250). However, as I see it, insofar as we do take such people to be 'as free' as those who have greater control over the dispositions they feel, such intuitions are mistaken. Rather, there is a definite sense in which they are 'less free' than others - even if they do not feel less free, or put any value on that lack of freedom - namely that they lack a specific freedom that others do not: that is, the freedom not to feel the particular disposition they are genetically predetermined to feel.
} 
our freedom than others by virtue of the fact that they are easily reversible, we might similarly think that some processes of self-conditioning are less concerning than others. One reason, then, why we might be relatively sanguine about conditioning techniques like the monk's is because it appears to be akin to a fairly benign BME, being slow to take effect (and hence giving plenty of time for the agent to reconsider), arguably temporary (seemingly requiring constant reaffirmation) and apparently reversible.

Second, it is worth re-emphasizing that, just as with the present analysis of BMEs, to identify a moral cost to the monk's actions is not to imply that they cannot be justified overall. Indeed, insofar as we find it difficult to see the moral cost of, say, the monk's actions, it may be that this is simply because we view the threat to the individuals' agency in this case is relatively minor and more than justified by the good it secures.

This talk of certain agency-denying strategies being 'overall justified' despite their moral cost brings us to another possible objection to the present analysis of BMEs. Let us say that, at this stage, proponents of biomedical moral enhancement are willing to accept all of the arguments that have been submitted thus far. Still, they might ask, even if this identifies one respect in which BMEs might be morally troubling, surely the potential benefits of such technologies are more than enough to outweigh these kinds of costs, especially when there may be cases in which the costs BMEs incurs are easily forestalled? ${ }^{49}$ This looks like a reasonable counter. However, it is worth emphasising here that making this argument in no way refutes any of the analysis offered thus far. That is, I am willing to accept that there may be possible benefits to taking BMEs, dependent or independent of the context in which they were taken, and which, considered individually or collectively, might render their use overall

\footnotetext{
${ }^{49}$ Cf. Douglas, Moral enhancement via direct emotion modulation, op. cit. note 3; DeGrazia, op. cit. note 21; Savulescu \& Persson, Moral enhancement, freedom and the God machine, op. cit. note 4.
} 
justified. However, the question about BMEs, as I took it, was not whether there are any benefits to taking BMEs, nor whether we can imagine a set of background conditions against which taking BMEs might become desirable or even morally obligatory (here we might think, for example, of Persson and Savulescu's defence of BMEs on the basis that it will help us avert an impending apocalypse). ${ }^{50}$ Rather the question was whether, whatever benefits we may come to associate with BMEs, there is any sense in which we might find them morally troubling, whether there are any costs they necessarily incur. And in this paper I have argued that there is: namely, the restriction they impose on our freedom.

Of course, in one sense, conceding both that, in some cases, the costs imposed by certain BMEs might be forestalled, and that, regardless, the use of some BMEs may still be overall justified, can seem to rob the present analysis of much of its argumentative force. However, I think this ignores how the present argument shifts the terms of the ethical debate around BMEs. First, insofar as the present analysis establishes at least one moral cost necessarily incurred by all BMEs, it means it is no longer enough for writers like Douglas to defend them simply on the grounds there is no reason to believe their use bears any moral costs whatsoever, for we have established that there is at least reason to think they do. Second, insofar as the argument set out in this article establishes a moral cost BMEs necessarily incur, we might also think that, if their use is nevertheless to be deemed allthings-considered justified, we need to know that their capacity to generate some set of countervailing benefits is, if not similarly inevitable, then more than merely possible. In other words, it is no longer enough for writers to defend the ethical desirability of BMEs simply on the basis that they may help us avert future challenges that may or may not come to pass (as

\footnotetext{
${ }^{50}$ For recent commentary on this position see, e.g., M. C. Azevedo. The misfortunes of moral enhancement. $J$ Med and Phil 2016; 41: 461-479.
} 
one might read, perhaps unfairly, Persson and Savulescu's defence of BMEs). Rather, if we are to consider the use of BMEs as overall justified, we need to know that these challenges are real ones, that the use of BMEs will help us in responding to them and that such benefits will be enough to outweigh their moral costs. For whether or not using BMEs will actually yield any potential benefits, it will necessarily come at a moral cost.

\section{Conclusion}

In this paper I have sought to establish what, if anything, might be morally troubling about morally enhancing oneself through biomedical means. Building on arguments by Harris, while simultaneously responding to several counter-arguments that have been put forth by his critics, I have argued that all BMEs necessarily incur at least one moral cost in the restrictions they impose on our freedom. This does not necessarily entail that there use cannot be justified, all things considered, nor that, in certain cases, their costs may not be forestalled. However, it does show that their use is not morally neutral. There is a cost to such technologies and, as such, the onus will always be on their defenders to show that such costs can compensated for. 